\title{
THEORIA
}

A Swedish Journal of Philosophy and Psychology

(All articles are in English, French, or German)

Editor: Professor Åke Petzäll, Lund, Sweden.

Manuscripts for publication in Theoria should be typewritten and addressed to the chief editor.

Financial correspondence should be addressed to Professor K. MarcWogau, Norbyvägen 18, Upsala, Sweden.

Annual subscription (3 parts) 12:50 Swed. $\mathrm{Kr}$.

Single parts 4:75 Swed. Kr.

Orders may'be sent to all booksellers or to the publishers, Messrs. C.W.K. Gleerup, Vårfrugatan 8, Lund, Sweden, or Messrs. Ejnar Munksgaard, Nørregade 6, Copenhagen K, Denmark.

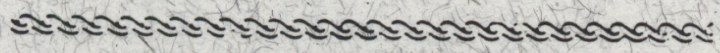

WILLARD VAN ORMAN QUINE'S

\section{From a Logical Point of View}

In this book, Mr. Quine concerns himself with semantics and adjacent areas of philosophy and logic. The material of the nine chapters is in part new and in part reprinted from a dozen articles in seven journals. Some of these articles are much cited in current philosophical literature; and in this book they are not only conveniently assembled, but variously reworked and rounded out with new essays to form an organized whole.

CONTENTS

On what there is.

Two dogmas of empiricism.

The problem of meaning in linguistics.

Identity, ostension, and hypostasis.
New foundations for mathematical logic*. Logic and the reification of universals. Notes on the theory of reference.

Reference and modality.

Meaning and existential inference.

- With supplementary remarks on subsequent developments.

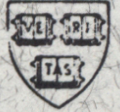

\section{HARVARD UNIVERSITY PRESS}

44 Francis Avenue - Cambridge 38, Massachusetts

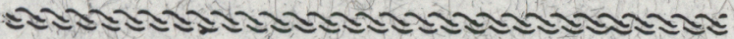




\title{
CARDANO, THE GAMBLING SCHOLAR
}

\section{BY OYSTEIN ORE}

Cardano was, among many other things, a devoted and skilled gambler who played for personal pleasure and profit. His mathematical genius enabled him to devise simple rules of probability for his own benefit and for his gambling contemporaries. These he collected in his Book on Games of Chance and embellished them with essays on the tricks of cheats and kibitzers, as well as on psychological rules of play.

In this biography of a stormy Renaissance personality, Cardano's gambling studies are deciphered for the first time, and a translation of the Book on Games of Chance is appended.

265 pages

$\$ 4.00$

\section{CONTRIBUTIONS to the THEORY of RIEMANN SURFATCES}

\author{
By L. AHLFORS, et al.
}

This book is the collection of papers given at the centennial celebration of Riemann's original dissertation. Twenty-one contributors present treatments of numerous problems and developments encountered in the subject today. The works of Dirichlet, Poincaré, Hilbert, and others are considered in addition to the author's original findings.

Annals of Mathematics Studies, No. 30

272 pages

\section{PRINCETON UNIVERSITY PRESS}

\author{
Princeton, New Jersey
}

